\title{
ISCHÆMIC HEART DISEASE AND PERIPHERAL OCCLUSIVE ARTERIAL DISEASE
}

\author{
BY \\ LAWSON MCDONALD \\ From the Department of Medicine, the Middlesex Hospital
}

Received September 19, 1952

Angina pectoris and intermittent claudication are well known to occur together in the same patient. The analogy between angina pectoris and pain in the legs in intermittent claudication has been recognized since Brodie drew attention to it in 1846, some years after Heberden's description of angina pectoris as a separate disease entity (Heberden, 1772), and preceding Charcot's description of intermittent claudication in man (Charcot, 1859). Angina pectoris in this paper has been taken to include angina of effort, cardiac infarction, or any intermediate syndrome such as coronary insufficiency (Master, 1946). Intermittent claudication may be defined as limping or lameness, often accompanied by pain in the leg, coming on during exercise.

It has been said that the term angina pectoris should be reserved for patients in whom cardiac pain is due to coronary artery disease (Parkinson, 1951), and this relationship has been known to exist for a long time (Black, 1795). Coronary artery disease is certainly the commonest cause of this type of cardiac pain, and atherosclerosis accounts for about 95 per cent of cases of coronary artery disease (Plotz, 1948; Wartman and Hellerstein, 1948). Similarly, it is now acknowledged that atherosclerotic occlusive arterial disease is the commonest cause of intermittent claudication (Boyd et al., 1949; Leriche, 1946; Lindbom, 1950; Luke, 1947), although this fact was temporarily obscured by Buerger's description of thromboangiitis obliterans in 1908 (Buerger, 1924; Weber, 1932). Subsequently, for many, intermittent claudication became synonymous with thromboangiitis obliterans, and if patients with the latter suffered from angina pectoris they were often considered to have thromboangiitis affecting the coronary arteries. Guillaume, amongst others, doubts whether thromboangiitis obliterans even exists as a separate disease entity (Guillaume, 1946); the authors cited above are at least agreed on its rarity. No proven case of it affecting the coronary arteries has been reported, and at least one authority on the pathology of arterial disease has never seen it (Dible, 1951).

Arteriosclerosis is widely acknowledged to be a generalized vascular disease (Allbutt, 1915; Aschoff, 1933; Dow; 1925); it might therefore be expected that two of its clinical manifestations, angina pectoris and intermittent claudication, might commonly occur together in the same patient. There have been numerous reports of such cases; some have been considered to be due to arteriosclerosis and others to thromboangiitis obliterans. But in view of what has already been written all that need be said is that they appear to have been examples of occlusive arterial disease affecting both the coronary and leg arteries.

The object of the present study was to determine how often angina pectoris and intermittent claudication, or the underlying occlusive arterial disease capable of producing either, occur together; this information is important in the treatment of a patient with either condition. The absence of angina pectoris or intermittent claudication in such patients will not exclude coronary or peripheral occlusive arterial disease capable of producing these symptoms, for either complaint may limit the 
patient's activity to a degree less than that required to bring on the other. Therefore objective evidence of these conditions must be sought, even though they are not subjectively manifest.

\section{SCOPE OF INVESTIGATION}

In this investigation 137 patients with occlusive arterial disease were studied; they presented with either angina pectoris or intermittent claudication. Eighty-seven patients with intermittent claudication were observed over a period of two years. Only those in whom the intermittent claudication was due solely to occlusive arterial disease were included; those with anæmia and coarctation of the aorta were excluded, also any in whom there was a possibility that arterial occlusion might have followed embolism. Fifty patients presenting during the same period with angina pectoris, either on effort or after cardiac infarction or as an intermediate syndrome between these two conditions were investigated. Patients whose cardiac pain might have been due to conditions other than coronary artery disease, such as luetic aortitis or severe anæmia, were excluded in the first instance.

In all patients presenting with intermittent claudication a full history was taken and clinical examination made; the blood pressure was estimated after at least fifteen minutes' rest in the recumbent posture. The following special investigations were performed: cardioscopy, blood count, blood Wasserman reaction, tonoscillography after exercise, and electrocardiography (usually leads I, II, III, unipolar chest leads V1 to V6, and augmented unipolar limb leads, VR, VL, and VF). Tonoscillography after exercise provides a useful diagnostic test of occlusive arterial disease affecting the legs (Ejrup, 1948; McDonald and Semple, 1952a and $b$ ); in some instances the diagnosis of occlusive arterial disease was further confirmed by arteriography or aortography. The patients who presented with angina pectoris were similarly investigated.

\section{RESULTS}

As this investigation was made to determine the coincidence of coronary and peripheral occlusive arterial disease, 6 of the 87 patients who presented with intermittent claudication were excluded, because they were found to have aortic valvular disease. Some of these suffered cardiac pain and others did not; but, if present, its source could not be assumed to be occlusive arterial disease. In analysing the results two other patients were excluded because it was known that they had been referred because they had both conditions. All the patients seen with intermittent claudication were considered to have occlusive arterial disease due to atherosclerosis and/or arterial thrombosis, except one who had juvenile obliterative arteritis (Boyd et al., 1949) or thromboangiitis obliterans. Of the remaining 79 patients presenting with intermittent claudication, 74 were men and 5 women. Twenty-three $(29 \%)$ had angina pectoris in addition to intermittent claudication. In thirteen the onset of the intermittent claudication preceded that of the angina pectoris, in six the angina pectoris developed earlier. The remaining four started both symptoms at about the same time. The resting electrocardiograms were found to be normal in 48 of the 79 patients; the remainder were abnormal (Wood, 1950). An ischæmic pattern was present in 7, of whom five did not give a previous history of angina pectoris. Evidence of cardiac infarction was found in 8 , and of these, three denied having had chest pain. There were 10 patients with a hypertensive pattern on the electrocardiogram. Left bundle branch block was present in 4; of these, two had angina pectoris and one hypertension, and no other heart disease was found clinically in the fourth, though the presence of left bundle branch block was considered to be suggestive, but not diagnostic, of ischæmic heart disease. There were 2 patients with right bundle branch block; one was hypertensive and the other had angina pectoris.

Therefore of the 56 patients with intermittent claudication who denied having angina pectoris eight $(14 \%)$ showed electrocardiographic evidence of ischæmic heart disease, and one changes suggestive of its presence. A diagnosis of ischæmic heart disease was made either subjectively 
$(29 \%)$ or objectively alone $(10 \%)$ in 31 of these 79 patients who presented with intermittent claudication (see Table I).

TABLE I

Seventy-Nine Patients Presenting with Intermittent Claudication

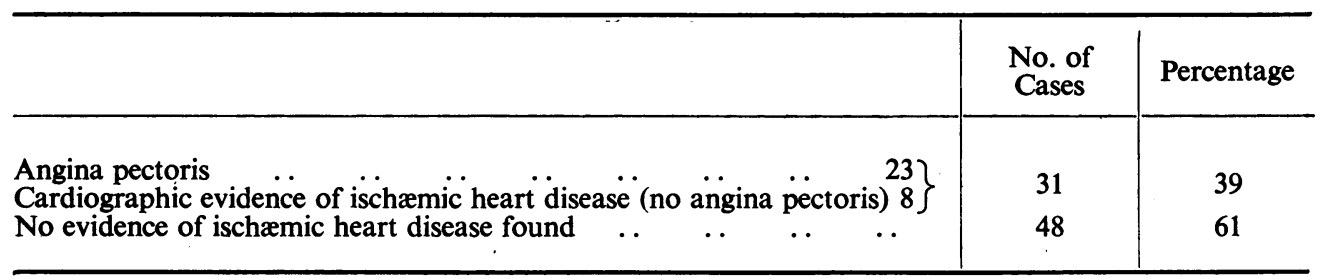

Of the 50 patients presenting with angina pectoris, 44 were men and 6 women. Four $(8 \%)$ suffered from intermittent claudication in addition to angina pectoris. One started to have angina pectoris before his intermittent claudication, and in one the intermittent claudication was the earlier of the two symptoms: the remaining two patients started to have these two complaints at about the same time. Eight $(17 \%)$ of the remaining 46 patients without intermittent claudication, showed objective evidence of occlusive arterial disease of the legs. Thus, a diagnosis of occlusive arterial disease affecting the legs was made either subjectively or objectively in 12 of the 50 patients presenting with angina pectoris (see Table II).

TABLE II

Fifty Patients Presenting with Angina Pectoris

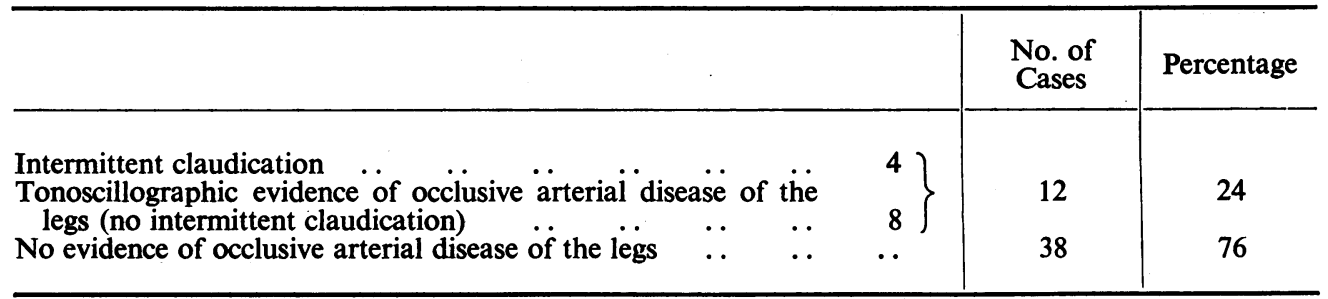

The blood Wasserman reaction was found to be negative in all patients, except one on whom the test was not performed. The electrocardiographic findings on the patients presenting with angina pectoris are not reported here, as these patients were selected solely because they gave an unequivocal history of angina pectoris.

It is therefore apparent that coronary and peripheral occlusive arterial disease often exist together. In the present study the estimate of their coincidence is probably conservative, for the following reasons. Firstly, in seven patients with intermittent claudication who were among those longest under observation, evidence of ischæmic heart disease only developed some months after they were first seen, and was not found initially. Others still under observation may be expected to run the same course. Secondly, the frequency with which resting electrocardiograms are normal in patients with ischæmic heart disease is well known. And thirdly, with the method of tonoscillography used in this study about 5 per cent of symptom-free patients with occlusive arterial disease affecting the legs could be missed.

The way in which these 129 patients presented at hospital appeared to be quite arbitrary, for some of those presenting with intermittent claudication gave a history of having developed angina pectoris first, and vice versa. Therefore, for purposes of comparison, they have been divided into three groups. 
Group 1. Patients with occlusive arterial disease of the legs, in whom no evidence of

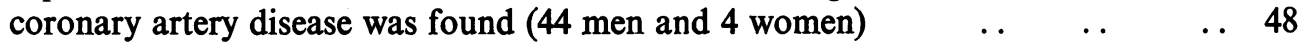

Group 2. Patients with occlusive arterial disease affecting both the coronary arteries

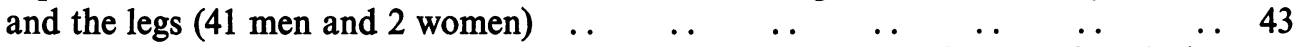

Group 3. Patients with coronary artery disease, in whom no evidence of occlusive

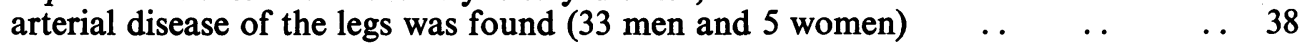

Sex. Throughout the series of 129 patients there was a preponderance of men over women, in a ratio of over ten to one; a preponderance was similarly found in each of the groups (see above).

Blood Pressure. This was classified as follows: (1) normal, with a blood pressure of $140 / 90$ or less; (2) borderline systolic hypertension with a systolic pressure over $140 \mathrm{~mm}$. $\mathrm{Hg}$; (3) mild hypertension with a diastolic pressure up to and including $110 \mathrm{~mm} . \mathrm{Hg}$ and (4) serious hypertension with a diastolic pressure over $110 \mathrm{~mm}$. Hg. Raised blood pressure was common (Table III). No significant difference was found in the distribution of hypertension amongst the three groups (males).

TABLE III

Distribution of LeVels of Blood Pressure

\begin{tabular}{c|c|c|c|c}
\hline Group & $\begin{array}{c}\text { Normal } \\
\text { blood } \\
\text { pressure } \\
(\%)\end{array}$ & $\begin{array}{c}\text { Borderline } \\
\text { systolic } \\
\text { hypertension } \\
(\%)\end{array}$ & $\begin{array}{c}\text { Mild } \\
\text { hypertension } \\
(\%)\end{array}$ & $\begin{array}{c}\text { Serious } \\
\text { hypertension } \\
(\%)\end{array}$ \\
\hline 1 & 46 & 27 & 19 & 8 \\
2 & 30 & 28 & 37 & 5 \\
3 & 32 & 16 & 42 & 10 \\
\hline
\end{tabular}

No woman had angina pectoris in the absence of hypertension, and only one out of six who presented with intermittent claudication had a normal blood pressure.

Age of Onset. The maximum period of onset was in the sixth decade. Those patients with intermittent claudication alone, or with both ischæmic heart disease and occlusive arterial disease of the legs, more often started to have symptoms in the second half of the sixth decade. Those with ischæmic heart disease alone showed a preponderance in the first half of the sixth decade. The earliest age of onset was in a man who started to have intermittent claudication at the age of 29 years; the latest age of onset was seen in two men who started to have intermittent claudication at the age of 77 years.

A family history of cardiovascular disease was frequently obtained in the present series of patients. Obesity was not uncommonly found in the patients examined in the present study.

\section{Discussion}

The results obtained in this study indicate the frequent association of ischamic heart disease and occlusive arterial disease of the legs; thorough investigation reveals a much higher coincidence of the two conditions than has previously been recorded, although there has been an increasing awareness of the likelihood of the presence of ischæmic heart disease in patients with occlusive disease of the legs (Hines and Barker, 1940; Leriche, 1946; Rossier, 1946; and Samuels, 1950). The dramatic picture of angina pectoris often ending in death has perhaps clouded the less impressive peripheral arterial disease. In a recent paper on the natural history of coronary disease the presence of other vascular disease (and this was not limited to disease affecting the legs) was recorded in only 4 per cent of men and 7 per cent of women (Ryle and Russell, 1949).

Diagnosis and Pathogenesis. The not infrequent occurrence of ischæmic heart disease in youth was particularly realized when so many young men came under careful medical supervision during and after the second world war (French and Dock, 1944; Yater et al., 1951); others had previously 
found the same (Glendy et al., 1937). In the present series of 50 patients presenting with angina pectoris 14 were under the age of fifty years. Similarly, intermittent claudication due to arteriosclerotic occlusive arterial disease is not uncommon amongst younger subjects (Boyd et al., 1949); 17 of the 87 patients who were examined in this study, or over 19 per cent, started to have intermittent claudication under the age of fifty years. Thromboangiitis obliterans should not be diagnosed solely because of the comparative youth of some patients with occlusive arterial disease.

Prognosis. Although it is difficult to make an accurate prognosis in an individual patient with ischæmic heart disease, the probable prognosis in this group of patients is well known (Parker et al., 1946; White et al., 1943). The prognosis in patients with occlusive arterial disease of the legs will obviously be greatly influenced by the presence or absence of co-existent ischæmic heart disease. In one series 55 per cent were found to die within three years of their first attendance at hospital (Hines and Barker, 1940): these authors wrote that " the majority died in a manner that was suggestive of coronary thrombosis." The present series of patients with occlusive arterial disease of the legs has not been observed long enough to determine the prognosis of the group, nor can one say if it is representative. But the findings so far, especially the high incidence of ischæmic heart disease, coincide with previous views on the serious prognosis in this condition. The addition of ischæmic heart disease to intermittent claudication cannot be regarded favourably, but this is not true of the reverse position. Repeated attacks of myocardial ischæmia must eventually have some permanent effect on the heart muscle; if intermittent claudication only prevents these episodes by halting the patient before their onset, it would seem likely to be of benefit. Previous work (Blumgart et al., 1950; Ravin and Geever, 1946; and Zoll et al., 1951a) would suggest that the patient who can achieve a balance between sufficient activity to produce mild anoxæmia (to stimulate the development of collaterals) and activity that produces anoxæmia sufficient to cause permanent damage is fortunate. Coincident intermittent claudication might help to achieve this.

Common Factors in Coronary and Peripheral Occlusive Arterial Disease. The results in this study illuminate various problems common to both coronary and peripheral occlusive arterial disease. These include the sex incidence of occlusive arterial disease, the association of hypertension, particularly with angina pectoris in women, the age of onset of symptoms, also the frequent occurrence of a family history of cardiovascular disease and of obesity, among these patients. In this series and in others there is a striking preponderance of men among those who have occlusive arterial disease of the legs (Hines and Barker, 1940; Lindbom, 1950). This is also so in those with coronary occlusive arterial disease (Master et al., 1939; Parker et al., 1946; and White et al., 1943). Angina pectoris is known to be rare in women in the absence of other heart disease; hypertension has been described as an important factor in its ætiology (Summers, 1948), although there is lack of agreement on its importance as such (Davis and Klainer, 1940; White et al., 1950). All the women in the present series presenting with angina pectoris also had hypertension. Of the 6 women among 87 presenting with intermittent claudication, five had hypertension and one normal blood pressure. In the 77 men who were found only to have evidence of either ischæmic heart disease or peripheral occlusive arterial disease, the incidence of hypertension was not significantly different in either group, nor between these two groups and those who had both conditions. The frequency with which hypertension is found in patients with coronary artery disease is well known (Cassidy, 1946; Master et al., 1939; and Zoll et al., 1951b); there seems also to be a high incidence of hypertension, as defined in this study, among patients with intermittent claudication.

The level of blood pressure has been considered to play a part in the localization and severity of atherosclerosis; the higher incidence of coronary disease in hypertensive subjects has been suggested as evidence of this. The effect of gravity is added to that of systolic hypertension as a possible factor in the greater frequency of atherosclerosis in the arteries of the legs than the arms (Dock, 1946); the higher systolic pressure and steeper pulse wave which are found at the bifurcation of the aorta have been considered to correspond with the higher incidence of atherosclerosis there than in the thoracic aorta (Dock, 1946; Hamilton and Dow, 1939). The much thicker intima found in the coronary arteries than in arteries of similar diameter elsewhere in the body, and the 
fact that these changes are greater in men than in women has been suggested to account for the sex difference in the incidence of coronary disease (Dock, 1946).

The maximum age of onset of symptoms found in the sixth decade in the present study corresponds with previous findings both in angina pectoris (Master et al., 1939; Parker et al., 1946) and in patients with intermittent claudication (Hines and Barker, 1940). The findings with regard to family history correspond with those of others in both angina pectoris (White, 1946) and intermittent claudication (Samuels, 1950). The common occurrence of obesity is of interest as it has been considered to be a factor in the incidence of at least some forms of arteriosclerosis (French and Dock, 1944), although this is not always completely accepted (Gregg, 1950).

Treatment. The results of this study are important with regard to the treatment of patients with angina pectoris or intermittent claudication; it should be realized that in treating either of these conditions the other may be liable to develop if it is not already present, or to become more severe if it is. Particularly before any surgical intervention is considered to relieve either peripheral or coronary occlusive arterial disease, a thorough examination of these patients should be undertaken; it may then be determined whether one symptom that limits the patient's activities should be replaced by another.

\section{SUMMARY}

137 patients with occlusive arterial disease, presenting with either angina pectoris or intermittent claudication were studied; it was found that these conditions, or the underlying disease capable of producing them, commonly coexisted. Men were more often affected than women, and hypertension was frequently associated. Other common features in these patients are discussed, and the importance of a thorough examination is emphasized from the point of view of their management.

It is a pleasure to acknowledge the help and encouragement received from Dr. D. Evan Bedford and Professor Alan Kekwick throughout this work, and to thank them and other members of the Consulting Staff of the Middlesex Hospital for permission to study their patients. I wish also to thank Dr. John Goodwin for useful criticism and Dr. Robert Semple for much helpful discussion and for taking some of the tonoscillograms.

This paper includes part of a thesis submitted for the M.D. degree at Cambridge University, and I am indebted to Sir Lionel Whitby, the Regius Professor of Physic, Cambridge University; for permission to publish it.

\section{REFERENCES}

Allbutt, C. (1915). Diseases of the Arteries, including Angina Pectoris. London, vol. II, p. 80.

Aschoff, L. (1933). In Arteriosclerosis: A Survey of the Problem, by Cowdry, E. V., New York, p. 14.

Black, S. (1795). Mem. med. Soc. Lond., 4, 261.

Blumgart, H. L., Zoll, P. M., Freedberg, A. S., and Gilligan, D. R. (1950). Circulation, 1, 10.

Boyd, A. M., Ratcliffe, A. H., Jepson, R. P., and James, G. W. H. (1949). J. Bone Jt. Surg., 31 B, 325.

Brodie, B. C. (1846). Lectures Illustrative of Various Subjects in Pathology and Surgery. London, p. 360.

Buerger, L. (1924). The Circulatory Disturbances of the Extremities. Philadelphia, p. 214.

Cassidy, M. (1946). Lancet, 2, 587.

Charcot, J. M. C. (1859). C.R. Soc. Biol. Paris, Série 2, 5, 225.

Davis, D., and Klainer, M. J. (1940). Amer. Heart J., 19, 185, 193, 198.

Dible, J. H. (1951). Personal communication.

Dock, W. (1946). J. Amer. med. Ass., 131, 875.

Dow, D. R. (1925). Brit. med. J., 2, 162.

Ejrup, B. (1948). Acta med. scand., 130, Suppl. 211.

French, A. J., and Dock, W. (1944). J. Amer. med. Ass., 124, 1233.

Glendy, R. E., Levine, S. A., and White, P. D. (1937). J. Amer. med. Ass., 109, 1775.

Gregg, D. E. (1950). Coronary Circulation in Health and Disease. London, p. 17.

Guillaume, A. C. (1946). Quoted in Thromboses Artérielles by Leriche, R., Paris, pp. 231, 268.

Hamilton, W. F., and Dow, P. (1939). Amer. J. Physiol., 125, 48.

Heberden, W. (1772). Medical Transactions published by the College of Physicians in London, 2, 59.

Hines, E. A., and Barker, N. W. (1940). Amer. J. med. Sci., 200, 717.

Leriche, R. (1946). Thromboses Artérielles. Physiologie Pathologique et Traitement Chirurgical. Avec la Collaboration d'Ivan Bertrand, Paris, pp. 183, 259, 476.

Lindbom, A. (1950). Acta radiol., Suppl. 80.

Luke, J. C. (1947). Canad. med. Ass. J., 56, 377.

McDonald, L., and Semple, R. (1952a). Brit. Heart J., 14, 91.

- (1952b). Proc. Roy. Soc. Med., 45, 497. 
Master, A. M. (1946). N. York Med., 2, 19. , Dack, S., and Jaffe, H. L. (1939). Arch. intern. Med., 64, 767.

Parker, R. L., Dry, T. J., Willius, F. A., and Gage, R. P. (1946). J. Amer. med. Ass., 131, 95.

Parkinson, J. (1951). Lancet, 2, 695.

Plotz, M. (1948). Amer. J. med. Sci., 215, 91.

Ravin, A., and Geever, E. F. (1946). Arch. intern. Med., 78, 125.

Rossier, P. H. (1946). Schweiz. med. Wschr., 37/38, 944.

Ryle, J. A., and Russell, W. T. (1949). Brit. Heart J., 11, 370.

Samuels, S. S. (1950). Management of Peripheral Arterial Disease. New York, pp. 175, 180.

Summers, V. K. (1948). Brit. Heart J., $10,4$.

Wartman, W. B., and Hellerstein, H. K. (1948). Ann. intern. Med., 28, 41.

Weber, F. P. (1932). Proc. Roy. Soc. Med., 26, 139.

White, N. K., Edwards, J. E., and Dry, T. J. (1950). Circulation, 1, 645.

White, P. D. (1946). Heart Disease. New York, p. 483. Bland, E. F., and Miskall, E. W. (1943). J. Amer. med. Ass., 123, 801.

Wood, P. (1950). Diseases of the Heart and Circulation. London, p. 83.

Yater, W. M., Welsh, P. P., Stapleton, J. F., and Clark, M. L. (1951). Ann. intern. Med., $34,352$.

Zoll. P. M., Wessler, S., and Blumgart, H. L. (1951b). Amer. J. Med., 11, 331. ,,- and Schlesinger, M. J. (1951a). Circulation, 4, 797. 